\title{
Endoscopic endonasal surgery for olfactory groove meningiomas: outcomes and limitations in 50 patients
}

\author{
Maria Koutourousiou, M.D. ${ }^{1}$ Juan C. Fernandez-Miranda, M.D. ${ }^{2}$ Eric W. Wang, M.D. ${ }^{3}$ \\ Carl H. Snyderman, M.D., M.B.A., ${ }^{2,3}$ and Paul A. Gardner, M.D. ${ }^{2}$
}

${ }^{1}$ Department of Neurological Surgery, University of Louisville, Kentucky; and Departments of ${ }^{2}$ Neurological Surgery and ${ }^{3}$ Otolaryngology, University of Pittsburgh Medical Center, Pittsburgh, Pennsylvania

\begin{abstract}
Object. Recently, endoscopic endonasal surgery (EES) has been introduced in the management of skull base tumors, with constantly improving outcomes and increasing indications. The authors retrospectively reviewed the effectiveness of EES in the management of olfactory groove meningiomas.

Methods. Between February 2003 and December 2012, 50 patients (64\% female) with olfactory groove meningiomas underwent EES at the University of Pittsburgh Medical Center. The authors present the results of EES and analyze the resection rates, clinical outcome, complications, and limitations of this approach.

Results. Forty-four patients presented with primary tumors, whereas six were previously treated elsewhere. The patients' mean age was 57.1 years (range 27-88 years). Clinical presentation included altered mental status (36\%), visual loss $(30 \%)$, headache (24\%), and seizures (20\%). The mean maximum tumor diameter was $41.6 \mathrm{~mm}$ (range $18-80 \mathrm{~mm})$. All patients underwent EES, which was performed in stages in 18 giant tumors. Complete tumor resection (Simpson Grade I) was achieved in $66.7 \%$ of the 45 patients in whom it was the goal, and $13(28.9 \%)$ had neartotal resection (>95\% of the tumor). Tumor size, calcification, and absence of cortical cuff from vasculature were significant factors that influenced the degree of resection $(\mathrm{p}=0.002, \mathrm{p}=0.024$, and $\mathrm{p}=0.028$, respectively). Tumor residual was usually at the most lateral and anterior tumor margins.

Following EES, mental status was improved or normalized in $77.8 \%$ of the cases, vision was improved or restored in $86.7 \%$, and headaches resolved in $83.3 \%$. There was no postoperative deterioration of presenting symptoms. Complications were increased in tumors $>40 \mathrm{~mm}$ and included CSF leakage (30\%), which was significantly associated with lobular tumor configuration $(\mathrm{p}=0.048)$; pulmonary embolism/deep vein thrombosis, more commonly in elderly patients (20\%); sinus infections (10\%); and delayed abscess months or years after EES (6\%). One patient had an intraoperative vascular injury resulting in transient hemiparesis $(2 \%)$. There were no perioperative deaths. During a mean follow-up period of 32 months (median 22 months, range 1-115 months), 1 patient underwent repeat EES for tumor regrowth.

Conclusions. Endoscopic endonasal surgery has shown good clinical outcomes regardless of patient age, previous treatment, or tumor characteristics. Tumor size $>40 \mathrm{~mm}$, calcification, and absence of cortical vascular cuff limit GTR with EES; in addition, large tumors are associated with increased postoperative complications. Significant lateral and anterior dural involvement may represent indications for using traditional craniotomies for the management of these tumors. Postoperative CSF leakage remains a problem that necessitates innovations in EES reconstruction techniques.
\end{abstract}

(http://thejns.org/doi/abs/10.3171/2014.7.FOCUS14330)

$\begin{array}{llclll}\text { KEY WoRDS } & \bullet & \text { endoscopic endonasal surgery } & \bullet & \text { endoscopic skull base surgery } & \bullet \\ \text { meningioma } & \bullet & \text { olfactory groove }\end{array}$

$\mathrm{M}$ ENINGIOMAS of the olfactory groove arise from the region of the frontosphenoidal suture and may involve any part of the area from the crista galli to the planum sphenoidale. ${ }^{21,31,35,39}$ Given their slow growth pattern and subfrontal location, olfactory groove

\footnotetext{
Abbreviations used in this paper: $\mathrm{ACA}=$ anterior cerebral artery; $\mathrm{CTA}=\mathrm{CT}$ angiography; DVT $=$ deep vein thrombosis; EEA = endoscopic endonasal approach; EES = endoscopic endonasal surgery; GTR = gross-total resection; NTR $=$ near-total resection; PE = pulmonary embolism; STR = subtotal resection; $\mathrm{VP}=$ ventriculoperitoneal.
}

meningiomas present insidiously and frequently achieve large size before detection..$^{21,39}$ Removal of small to midsize tumors usually is not difficult, but resecting large tumors and/or those that infiltrate or surround adjacent structures becomes challenging.

Various surgical approaches have been advocated to resect olfactory groove meningiomas, with the subfrontal (unilateral or bilateral) and pterional approaches being the most popular., $1,4,6,11,20,21,31,39$ Recently, technological advances (angled endoscopes, specialized instrumentation, image guidance, neurophysiological monitoring) and increasing experience have expanded the indications 


\section{Koutourousiou et al.}

of endoscopic endonasal surgery (EES) to include anterior skull base meningiomas. ${ }^{7,8,12,13,16-18,24,26,37}$ Endoscopic endonasal surgery provides panoramic visualization and wide access to the anterior skull base from below, allowing for total resection of the involved/diseased bone and mucosa and early devascularization of the tumor with no frontal lobe manipulation. Large tumors with encasement of the surrounding arteries remain challenging to treat regardless of the approach, but EES presents its own advantages and limitations.

In this paper we present our experience in the management of tumors in 50 patients with olfactory groove meningiomas treated with EES. We analyze the benefits of this technique and study the variables that limit surgical success. To our knowledge, this is one of the largest surgical series of olfactory groove meningiomas and represents the widest documented surgical experience with EES.

\section{Methods}

\section{Patient Population}

With approval of the institutional review board, we retrospectively reviewed the medical files and imaging studies in patients with olfactory groove meningiomas treated with EES at the University of Pittsburgh Medical Center between February 2003 and December 2012. Fifty-two patients with olfactory groove meningiomas were identified; however, 2 were excluded from the study, one because of missing data for analysis and the other because EES was aborted and converted to craniotomy due to the extremely fibrotic consistency of the tumor. Notably, both of these cases were treated in the very first years of using EES, with limited surgical experience and instrumentation. One patient presented with 2 distinct anterior cranial fossa meningiomas of the olfactory groove and the planum sphenoidale that were treated at the same time with a single endoscopic endonasal approach (EEA).

\section{Imaging Findings}

Every patient had preoperative imaging studies, including MRI studies available in 46 patients and fine-cut CT or CT angiography (CTA) studies in all but 2 patients. The studied parameters were maximum tumor diameter (in millimeters); tumor volume, using the modified ellipsoid formula $\left(\mathrm{A}^{*} \mathrm{~B} * \mathrm{C}\right) / 2$; the presence of hyperostotic bone and calcified tumor (on CT/CTA studies, when available); tumor shape (rounded vs lobular); vascular encasement (on CTA and T2-weighted MRI); optic canal invasion (on fine-cut axial T1-weighted, postcontrast MRI/ $\mathrm{CT}$ ); and the presence of cortical cuff between the tumor and anterior cerebral vasculature.

\section{Surgical Management}

All patients underwent purely EES with the previously described 2-surgeon technique. ${ }^{17}$ The goal of surgery was gross-total resection (GTR) of the tumor in all but 5 elderly or high-risk surgical patients with multiple comorbidities. To prevent extensive blood loss, prolonged surgical and anesthesia time, and surgeon fatigue, EES was staged when necessary. Only 1 patient had craniotomy (orbitozygomatic frontotemporal) as a third-stage approach. In this case, the indication for open craniotomy was based on the extreme fibrosity of the tumor in combination with young patient age and the goal of GTR.

\section{Evaluation of Surgical Results}

Clinical outcome after EES was assessed with documented clinical status, physical examination, and postoperative visual tests (visual acuity and visual fields). The degree of tumor resection was evaluated on postoperative imaging studies and included MRI in all but 2 patients, who had a CT instead. The degree of tumor resection was evaluated with volumetric analysis (postoperative tumor volume compared with preoperative) on immediate postoperative studies (available in every case) and confirmed at 3 months postoperatively in all but 4 cases. Gross-total resection, defined as Simpson Grade I resection, was assessed among 45 patients; GTR was not the goal of surgery in the other 5. When GTR was not achieved, the volume of residual tumor was measured and the degree of resection classified as near-total resection (NTR) when $\geq 95 \%$ of the tumor was removed, and subtotal resection (STR) for $<95 \%$ removal.

The length of follow-up was evaluated based on the most recent MRI studies. Lack of available follow-up was usually due to distance of the patient from our center.

\section{Statistical Analysis}

Patient demographic data, clinical presentation, tumor characteristics, surgical approaches, and outcomes were analyzed using descriptive statistics. The GTR rates for every studied tumor characteristic were compared using the chi-square and Fisher exact tests within the studied variable. A p value $<0.05$ was considered statistically significant. Data were collected using Microsoft Excel 2010 (Microsoft Corp.) and were analyzed using SAS 9.3 (SAS Institute, Inc.).

\section{Results}

\section{Pathological Entities and Demographic Data}

In every case the diagnosis was histologically confirmed, and diagnoses included 49 benign meningiomas (WHO Grade I) and 1 atypical meningioma (WHO Grade II). Patient age ranged from 27 to 88 years (mean 57.1 years) and there was a clear female predominance $(64 \%$ female), with a male/female ratio of 1:1.8. Among the 50 patients, 44 had primary tumors $(88 \%)$ and $6(12 \%)$ were previously treated elsewhere (with craniotomy in every case and additional radiation therapy in 1 case).

\section{Clinical Presentation}

The dominant clinical symptom at presentation was impaired mental status in 18 patients (36\%), including decreased cognition, memory loss, personality changes, and mood disorders. Visual loss occurred in 15 cases (30\%); it was associated with papilledema in 8 patients and was more common in tumors $>40 \mathrm{~mm}(\mathrm{p}=0.004)$. Papillede- 


\section{Endoscopic endonasal surgery for olfactory groove meningiomas}

ma was present in every patient with hydrocephalus, and every patient with hydrocephalus presented with a sizable tumor ( $>40 \mathrm{~mm}$ in maximum diameter). Seizure was a presenting symptom in $20 \%$ of the patients; one patient with seizures had a prior craniotomy and another one had a coexisting convexity meningioma. Interestingly, only 8 patients complained of anosmia; however, smell status was not tested with objective criteria in cases of persistent olfaction. In 10 cases the patients were asymptomatic and, not surprisingly, all of them had tumors $\leq 40 \mathrm{~mm}$ in maximum diameter ( $\mathrm{p}=0.0001$ when compared with tumors $>40 \mathrm{~mm}$ ). As expected, the incidence of signs and symptoms was proportional to tumor size. In Table 1 , clinical presentations are categorized according to the tumor size.

\section{Imaging Findings}

Tumor size varied between 18 and $80 \mathrm{~mm}$, with a mean maximum diameter of $41.6 \mathrm{~mm}$. The average tumor volume was $29.5 \mathrm{~cm}^{3}$ (range 1.2-95.5 $\mathrm{cm}^{3}$ ). Hyperostotic bone at the tumor's base was identified in 31 cases $(62 \%)$ and tumor calcification in $13(26 \%)$. In only 15 cases $(30 \%)$, a cortical cuff around the tumor was evident, preventing any contact between the tumor and the anterior cerebral artery (ACA) or its branches; not surprisingly, a cortical cuff was found in smaller tumors (mean maximum tumor diameter of $29 \mathrm{~mm}$ in the presence of cortical cuff vs $47.5 \mathrm{~mm}$ in the absence of cortical cuff). In the remaining 35 cases $(70 \%)$, direct vascular contact with the tumor was noticed. However, in only 7 cases (14\%), true vascular encasement was found on preoperative images and confirmed intraoperatively. Encased arteries were usually frontopolar $(n=5)$ and $A_{2}$ segments of the ACA $(n=2$, bilateral in 1$)$. Tumor was rounded in 40 cases $(80 \%)$ and had a lobular configuration in $10(20 \%)$. Vascular encasement was associated with tumor shape, with $40 \%$ encasement on lobular tumors (4 of 10 cases) and only $7.5 \%$ in rounded tumors (3 encasements among 40 cases). In 10 cases (20\%), unilateral or bilateral tumor extension toward the medial aspect of the optic canal was noticed and confirmed intraoperatively.

\section{Surgical Management}

All 5 patients who presented with hydrocephalus and coexisting papilledema underwent ventriculoperitoneal (VP) shunt placement before EES. The remaining patients with papilledema required either external ventricular drainage before surgery and/or VP shunt placement after surgery. Endoscopic endonasal surgery was customized for the location and extent of the tumor and included combinations of transcribriform, transplanum, and transtuberculum approaches (Table 2). In 2 cases of relatively small tumors of unilateral origin, a unilateral/single-nostril EEA was used. Endoscopic optic nerve decompression was performed not only in cases of optic canal invasion by the tumor but also when patients presented with visual loss and papilledema.

The EEA extended beyond the borders of the tumor in almost every case to access and remove the involved dura mater and abnormal bone to achieve true GTR (Simpson Grade I). By these means, removal of the lamina papyracea was necessary in every case to apply gentle retraction of the periorbita and achieve access to the medial aspect of the orbital roof (superomedial orbitectomy). In 18 patients we used staged approaches, with a second EEA in all of them; almost all of the staged cases were giant tumors with an average maximum diameter of $52 \mathrm{~mm}$. An open craniotomy was performed as a third stage in 1 patient in whom the goal of GTR could not be achieved with EES due to the fibrous tumor consistency that prevented the tumor from descending after staged EES. As part of the initial management, 2 patients received adjuvant radiosurgery for residual tumor.

Lumbar drains were not used routinely after EES, and they were used in 10 cases in the series. In the early years of EEA when the vascularized flap was not used, the reconstruction was usually performed with regenerative tissue matrix (human dermis products) and reinforced with fat graft. With the routine use of vascularized flap, additional tissue matrix is usually applied when the flap does not cover the entire skull base defect.

The operating time for EES ranged from 137 to 820 minutes, with an average EES time of 530 minutes (8 hours, 50 minutes).

\section{Clinical Outcome}

Presenting deficits either improved or remained unchanged following EES, and none of the patients showed

TABLE 1: Clinical presentation of 50 patients with olfactory groove meningiomas in total and according to tumor size

\begin{tabular}{lcccc}
\hline \multicolumn{1}{c}{ Clinical Presentation } & No. w/ Tumors $\leq 40 \mathrm{~mm}(\%)$ & No. w/ Tumors $>40 \mathrm{~mm}(\%)$ & p Value & Total (\%) \\
\hline no. of patients & 22 & 28 & & 50 \\
changed mental status & $5(22.7)$ & $13(46.4)$ & 0.083 & $18(36)$ \\
visual loss & $2(9.1)$ & $13(46.4)$ & 0.004 & $15(30)$ \\
headache & $5(22.7)$ & $7(25)$ & 0.852 & $12(24)$ \\
seizures & $5(22.7)$ & $5(17.9)$ & 0.732 & $10(20)$ \\
anosmia & $1(4.5)$ & $7(25)$ & 0.064 & $8(16)$ \\
hydrocephalus & 0 & $5(17.9)$ & 0.059 & $5(10)$ \\
ambulation difficulties & $1(4.5)$ & $1(3.6)$ & 1.0 & $2(4)$ \\
incidental finding & $10(45.4)$ & 0 & 0.0001 & $10(20)$ \\
\hline
\end{tabular}

* Significant $p$ values are in boldface. 


\section{Koutourousiou et al.}

TABLE 2: Endoscopic endonasal approaches used to treat 50 patients with olfactory groove meningiomas

\begin{tabular}{lc}
\hline \multicolumn{1}{c}{ EEAs } & No. of Cases $(\%)$ \\
\hline transcribriform & $50(100)$ \\
transplanum & $42(84)$ \\
transtuberculum & $14(28)$ \\
optic nerve decompression & $16(32)$ \\
unilat & $2(4)$ \\
bilat & $14(28)$ \\
\hline
\end{tabular}

permanent worsening of clinical symptomatology. Only 1 had a transient visual deterioration as a result of papilledema associated with postoperative increased intracranial pressure that resolved following VP shunt placement.

Among 18 patients who presented with impaired mental status, $14(77.8 \%)$ were improved or returned to normal. Among patients with smaller tumors, there was a trend toward better outcome that did not reach statistical significance $(\mathrm{p}=0.278)$. Visual problems were improved in $86.7 \%$ of the cases. Headaches were also resolved in $83.3 \%$. Two patients with small tumors who presented with seizures remained seizure free without medications after EES, and all the others have attained seizure control with antiepileptic treatment. Every patient with hydrocephalus had a preoperative VP shunt placement, and showed resolution of imaging and clinical signs of hydrocephalus. Ambulation problems were improved in every case, and patients who were asymptomatic at presentation remained intact following surgery (Table 3 ).

To better understand the benefits of EES, we analyzed clinical improvement (focused on the main presenting symptoms of decreased mental status and vision) for different parameters (Table 4). The analysis included patient age, tumor size and volume, and degree of resection. Maximum tumor diameter of $40 \mathrm{~mm}$ and tumor volume of $30 \mathrm{~cm}^{3}$ were used as cutoffs representing the closest values to the average tumor size and volume in the cohort (mean $41.6 \mathrm{~mm}$ and $29.5 \mathrm{~cm}^{3}$, respectively). We found that clinical improvement was not significantly different in any studied parameter, reflecting the effectiveness of
TABLE 4: Improved mental status and vision assessed by different parameters in patients with olfactory groove meningiomas

\begin{tabular}{ccc}
\hline Parameter & $\begin{array}{c}\text { No. w/ Improved } \\
\text { Mental Status (\%) }\end{array}$ & $\begin{array}{c}\text { No. w/ Improved } \\
\text { Vision (\%) }\end{array}$ \\
\hline no. of patients & 18 & 15 \\
age $<65$ yrs & $6 / 8(75)$ & $11 / 13(84.6)$ \\
age $\geq 65 \mathrm{yrs}$ & $8 / 10(80)$ & $2 / 2(100)$ \\
$\mathrm{p}$ value & 1.0 & 1.0 \\
tumor size $\leq 40 \mathrm{~mm}$ & $5 / 5(100)$ & $1 / 2(50)$ \\
tumor size $>40 \mathrm{~mm}$ & $9 / 13(69.2)$ & $12 / 13(92.3)$ \\
$\mathrm{p}$ value & 0.278 & 0.257 \\
tumor vol $\leq 30 \mathrm{~cm}^{3}$ & $6 / 8(75)$ & $2 / 3(66.7)$ \\
tumor vol $>30 \mathrm{~cm}^{3}$ & $8 / 10(80)$ & $11 / 12(91.7)$ \\
$\mathrm{p}$ value & 1.0 & 0.371 \\
GTR & $6 / 9(66.7)$ & $3 / 5(60)$ \\
non-GTR & $8 / 9(88.9)$ & $10 / 10(100)$ \\
$\mathrm{p}$ value & 0.576 & 0.095 \\
total & $14 / 18(77.8)$ & $13 / 15(86.7)$ \\
\hline
\end{tabular}

EES regardless of patient age, tumor characteristics, and degree of resection.

The length of hospital stay ranged from 1 to 65 days, with an average stay of 11 days (median 6 days), which is longer than the hospital stay following EEA for other pathological entities and probably explains the increased deep vein thrombosis (DVT) and pulmonary embolism (PE) rates of this series (described below).

\section{Degree of Tumor Resection}

Among the 45 patients in whom it was the goal of surgery, GTR (Simpson Grade I) was achieved in 30 (66.7\%) (Fig. 1). In the remaining 15 patients, 13 (28.9\%) had NTR (> 95\% of the tumor) and $2(4.4 \%)$ had STR (Figs. 2 and 3). In total, 43 of these 45 patients (95.6\%) had a tumor resection $>95 \%$. In the 5 patients in whom GTR was not the goal of surgery, the degree of tumor resection varied between $50 \%$ and $90 \%$ of the initial tumor; this group included mainly elderly patients $(4$ were $>75$

TABLE 3: Clinical outcome following EES in 50 patients with olfactory groove meningiomas

\begin{tabular}{|c|c|c|c|c|c|c|c|}
\hline \multirow[b]{2}{*}{ Initial Deficit } & \multirow{2}{*}{$\begin{array}{c}\text { No. of } \\
\text { Patients }\end{array}$} & \multicolumn{3}{|c|}{ No. Improved/Resolved (\%) } & \multicolumn{3}{|c|}{ No. Unchanged (\%) } \\
\hline & & $\mathrm{w} /$ Tumors $\leq 40 \mathrm{~mm}$ & $\mathrm{w} /$ Tumors $>40 \mathrm{~mm}$ & Total & $\mathrm{w} /$ Tumors $\leq 40 \mathrm{~mm}$ & $\mathrm{w} /$ Tumors $>40 \mathrm{~mm}$ & Total \\
\hline changed mental status & 18 & $5 / 5(100)$ & $9 / 13(69.2)$ & $14 / 18(77.8)$ & 0 & $4 / 13(30.8)$ & $4 / 18(22.2)$ \\
\hline visual loss & 15 & $1 / 2(50)$ & $12 / 13(92.3)^{*}$ & $13 / 15(86.7)$ & $1 / 2(50)$ & $1 / 13(7.7)$ & $2 / 15(13.3)$ \\
\hline headache & 12 & $5 / 5(100)$ & $5 / 7(71.4)$ & 10/12 (83.3) & 0 & $2 / 7(28.6)$ & $2 / 12(16.7)$ \\
\hline seizures & 10 & $2 / 5(40) \dagger$ & 0 & $2 / 10(20)$ & $3 / 5(60)$ & $5 / 5(100)$ & $8 / 10(80)$ \\
\hline hydrocephalus & 5 & 0 & $5 / 5(100) \ddagger$ & $5 / 5(100) \ddagger$ & 0 & 0 & 0 \\
\hline ambulation difficulties & 2 & $1 / 1(100)$ & $1 / 1(100)$ & $2 / 2(100)$ & 0 & 0 & 0 \\
\hline incidental finding & 10 & 0 & 0 & 0 & $10 / 10(100)$ & 0 & $10 / 10(100)$ \\
\hline
\end{tabular}

* One case with transient deterioration due to hydrocephalus that improved after shunt placement.

$\dagger$ Free of seizure without medications.

$\ddagger$ All improved after shunt placement. 


\section{Endoscopic endonasal surgery for olfactory groove meningiomas}
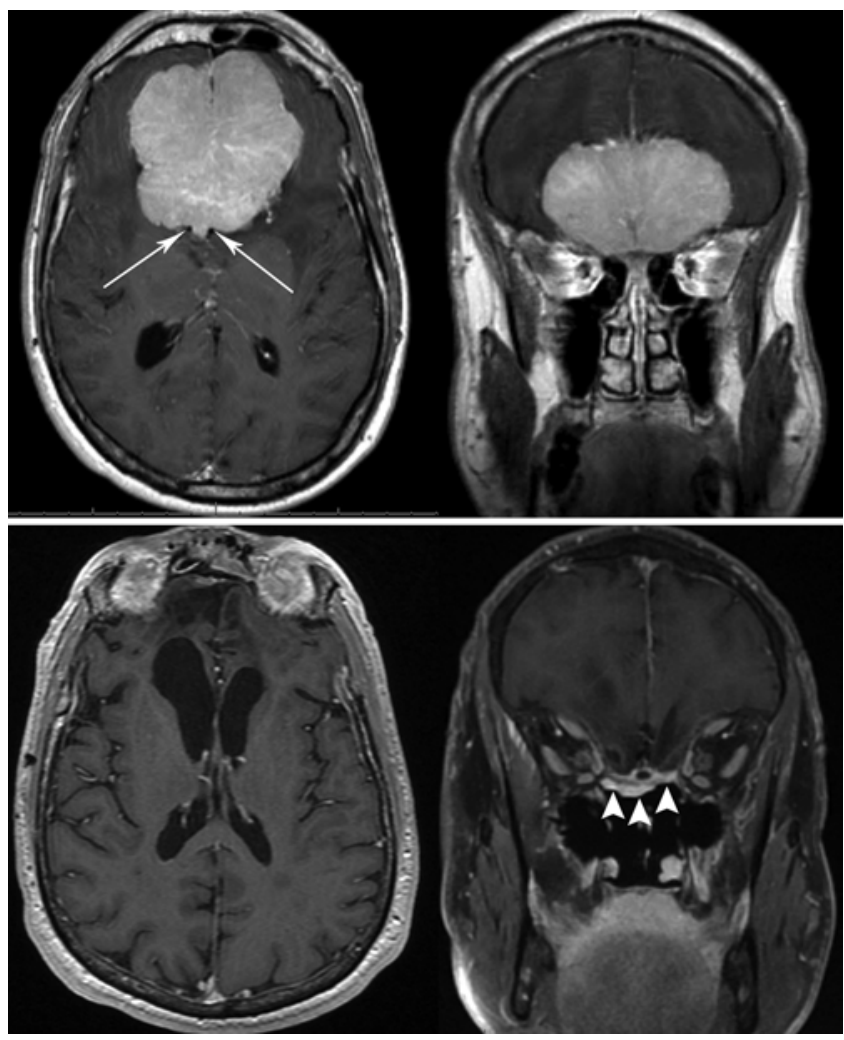

FIG. 1. Giant olfactory groove meningioma managed with staged EES. Upper: Preoperative axial and coronal MRI studies obtained after contrast administration illustrating a large meningioma with maximum diameter of $80 \mathrm{~mm}$ occupying the whole anterior cranial fossa. The patient presented with decreased cognition. Bilateral $A_{2}$ arteries are partially encased by the tumor (arrows), and the right frontopolar artery is completely encased (not shown in these images). Lower: Postoperative axial and coronal MRI studies obtained after contrast administration demonstrating GTR of the tumor after 2 EESs. The linear enhancing area along the skull base (arrowheads) represents the vascularized nasoseptal flap that was used for the reconstruction. During 31 months of follow-up, the patient has shown no tumor recurrence and is neurologically intact.

years of age) with significant medical comorbidities; thus, we avoided aggressive surgery and staged procedures. Of note, all of them experienced clinical improvement following EES and none of them suffered a stroke or any surgery-related complication.

To better understand the advantages and limitations of EES in olfactory groove meningioma resection, we analyzed the rate of GTR in the 45 patients according to patient age, previous treatment, tumor size/shape/volume, evidence of vascular encasement, hyperostotic bone, calcified tumor, and presence of a cortical cuff between tumor and vasculature. Table 5 summarizes the GTR rates of the 45 patients according to specific tumor parameters. Patient age, previous treatment, tumor volume, shape of the free surface of the meningioma, vascular encasement, and presence of hyperostotic bone are not limitations of GTR with EES.

The factors that significantly limited resection via EES were tumor size $(p=0.002)$, the presence of calcified tumor $(p=0.024)$, and the absence of a cortical cuff $(p=0.028)$. Tumors with maximum diameter of $\leq 40$ mm showed a GTR rate of $90.5 \%$, whereas this rate was only $45.8 \%$ in tumors $>40 \mathrm{~mm}$. Calcified tumors were more difficult to resect totally (GTR of $41.7 \%$ vs $80.6 \%$ in noncalcified tumors). Although vascular encasement as a single factor was not a significant limitation of the success of EES, the absence of a cortical cuff, which is also associated with sizable tumors as described above, had a compelling impact on the degree of tumor resection.

To understand the impact of the learning curve in achieving GTR of olfactory groove meningiomas, we separated the cohort of 45 patients with the goal of GTR into 3 sequential groups of 15 patients each, and studied the degree of tumor resection in every group. As shown in the graph (Fig. 4), the GTR rate was $<50 \%$ in the 1st third, and we encountered 2 cases with STR $(<95 \%$ of the tumor). Increasing the surgical experience, the GTR rate during the following years reached $80 \%$, and all patients underwent tumor resection $>95 \%$ in the second and third groups.

The most common location of residual tumor in the 13 cases with NTR was at the orbital roof (dura tail residual as depicted in Figs. 3 and 5) in 6 cases (46\%), attached to the optic nerve or frontopolar artery in 4 cases (31\%), and at the most anterior aspect of the falx in 3 cases $(23 \%)$.

\section{Complications and Management}

The most common surgical complication was postoperative CSF leakage, which occurred in 15 patients (30\%); it was managed with repeat surgery in every case and necessitated the use of an extracranial pericranial flap in 2 cases. There was only 1 case of postoperative meningitis (2\%), which occurred following CSF leakage and was treated with antibiotics, without further complications.

Ten patients (20\%) suffered a PE or DVT during the postoperative course (5 patients with PE and 5 with DVT); this complication was more common in tumors $>40 \mathrm{~mm}$ and in elderly patients, probably because of coexisting comorbidities and the necessity of longer hospitalization, and was managed with anticoagulation and/or inferior vena cava filter placement. Sinus infections occurred in 5 patients (10\%); they were treated with antibiotics alone in 2 cases and required maxillary or frontal sinus drainage in 3 cases. Four patients developed respiratory failure, usually following pneumonia or PE after prolonged ICU stay; these patients required a tracheostomy for several days. Three cases of postoperative hydrocephalus were managed with VP shunt placement. Intracranial abscess formation developed in 3 patients $(6 \%)$ several months or years after EES, without evidence of delayed or undiagnosed CSF fistula. Abscess formation was associated with tumors $>40$ $\mathrm{mm}$ and multiple surgeries, either for CSF leak repair or staging; all were managed with a combination of antibiotics and drainage without any neurological sequelae. One patient suffered a stroke and transient hemiparesis after frontoorbital artery pseudoaneurysm rupture; he required craniotomy for hematoma evacuation and aneurysm repair and had a good neurological recovery. Two patients developed seizures 2 years after EES and they are currently being treated with anticonvulsants. Table 6 summarizes the 

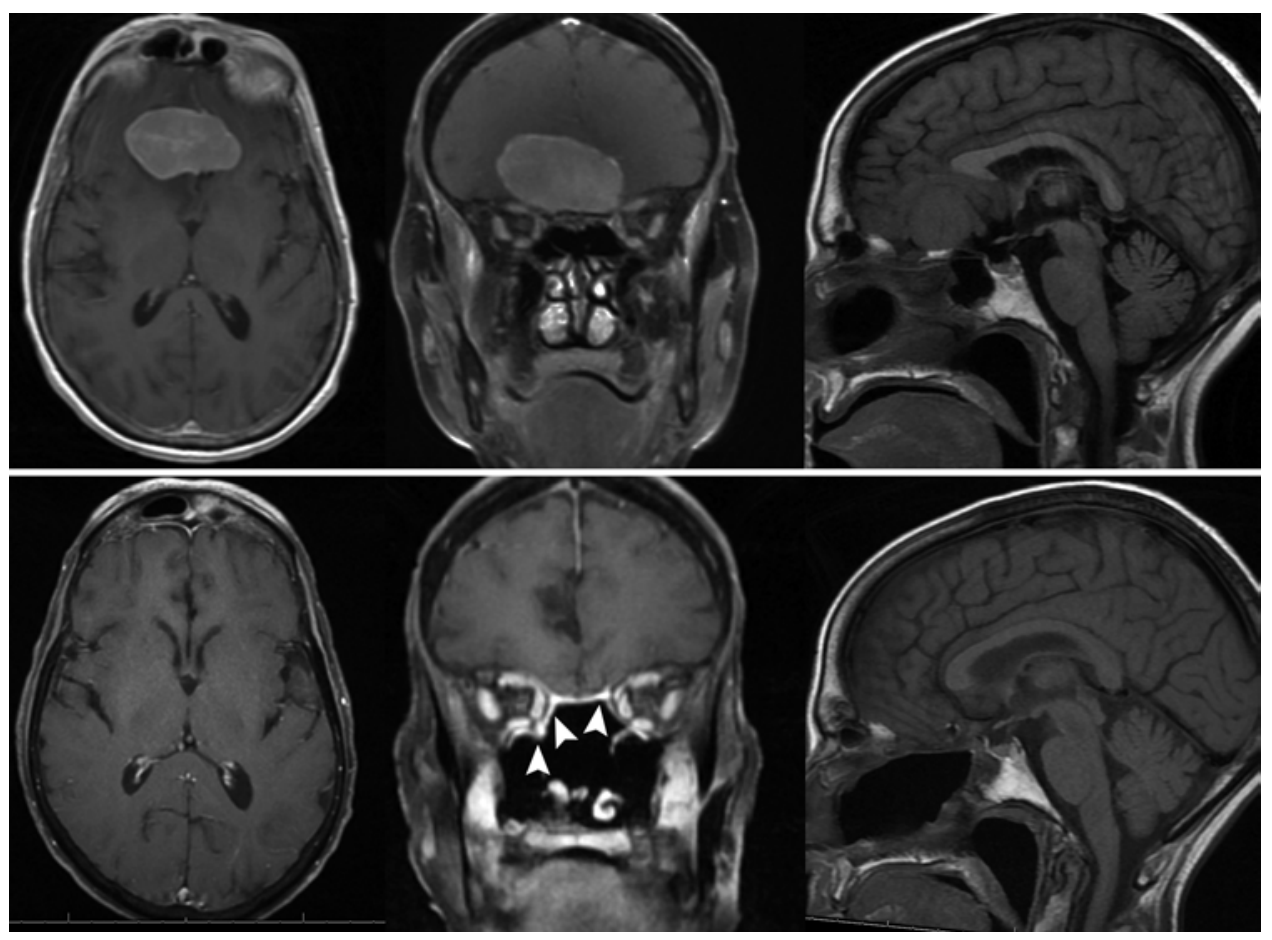

FIG. 2. Olfactory groove meningioma managed with EES. Upper: Preoperative axial and coronal MRI studies obtained with contrast and sagittal MRI obtained without contrast illustrating a rounded meningioma with maximum diameter of $50 \mathrm{~mm}$ originating from the cribriform plate and planum sphenoidale. The patient presented with headache and mood disorder. Lower: Postoperative axial and coronal MRI studies obtained with contrast and sagittal MRI obtained without contrast after a single EEA. Although no residual lesion is shown on the postoperative examinations, per the operative notes a small residual capsule was left attached to the right frontopolar artery, so it was considered an NTR. The linear enhancing area along the skull base (arrowheads) represents the vascularized nasoseptal flap. In 1 year of follow-up there has been no tumor regrowth, and the patient is neurologically intact.

complications in the whole cohort and for different age groups, tumor sizes, and number of surgeries; although the complication rates vary for different parameters and they were increased in large tumors, we found no statistically significant differences among these groups.

Trying to better understand and explain the increased rates of postoperative CSF leakage, we analyzed this complication for different parameters. During the years of routine use of vascularized flap (after 2007) the CSF leak rate was $29.4 \%$, which was not significantly different from the preflap-era leak rate of $31.2 \%$, indicating that there are factors other than the nasal flap reconstruction technique that determine the risk of CSF leakage; it worthwhile to note, however, that in the early years (before 2007) there was a limited dural opening and less tumor resection, and therefore a smaller skull base defect, which may introduce bias in the comparison of the two time periods.

Indeed, we studied our complications for different patient ages, tumor characteristics, degrees of resection, and surgical techniques (Table 7) to evaluate which factors predispose patients to increased CSF leakage. Our findings showed that more difficult tumors to treat (recurrent, sizable, with vascular encasement, calcified, with hyperostotic bone, and with absence of cortical cuff) also have higher rates of postoperative CSF leakage. However, the configuration of the free surface of the meningioma was the single significant factor associated with increased CSF leak rates; given that multilobular tumors require more extensive arachnoid dissection during surgery, there may be an association between increased CSF leakage and violation of multiple subarachnoid spaces during EES. Nonetheless, 8 of the 10 multilobular tumors in this cohort were sizable tumors ( $>45 \mathrm{~mm}$ ), raising suspicions regarding whether the increased CSF leakage in this category is a combination of large tumor size and irregular shape that requires extensive surgical manipulation.

Of note, the CSF leak rate decreased to $20 \%$ during the most recent 15 cases, indicating the impact of the learning curve in reducing this surgery-related complication. The single case of vascular injury in this cohort occurred during the early years of EES for olfactory groove meningiomas (2005). Every other complication occurred at a similar rate recently and in the past, suggesting that other factors than the learning curve are associated with their occurrence.

\section{Recurrence and Follow-Up}

During the mean follow-up period of 32.2 months (median 22 months, range $1-115$ months), 3 patients (6\%) showed tumor recurrence; 2 of them had undergone GTR and 1 NTR. The mean recurrence-free period was 40 months (range 24-63 months). Two patients were treated with radiosurgery alone and 1 with repeat EES and adjuvant radiosurgery. All of them have unchanged tumor size and they remain clinically stable during a mean follow-up of 73 months. 


\section{Endoscopic endonasal surgery for olfactory groove meningiomas}

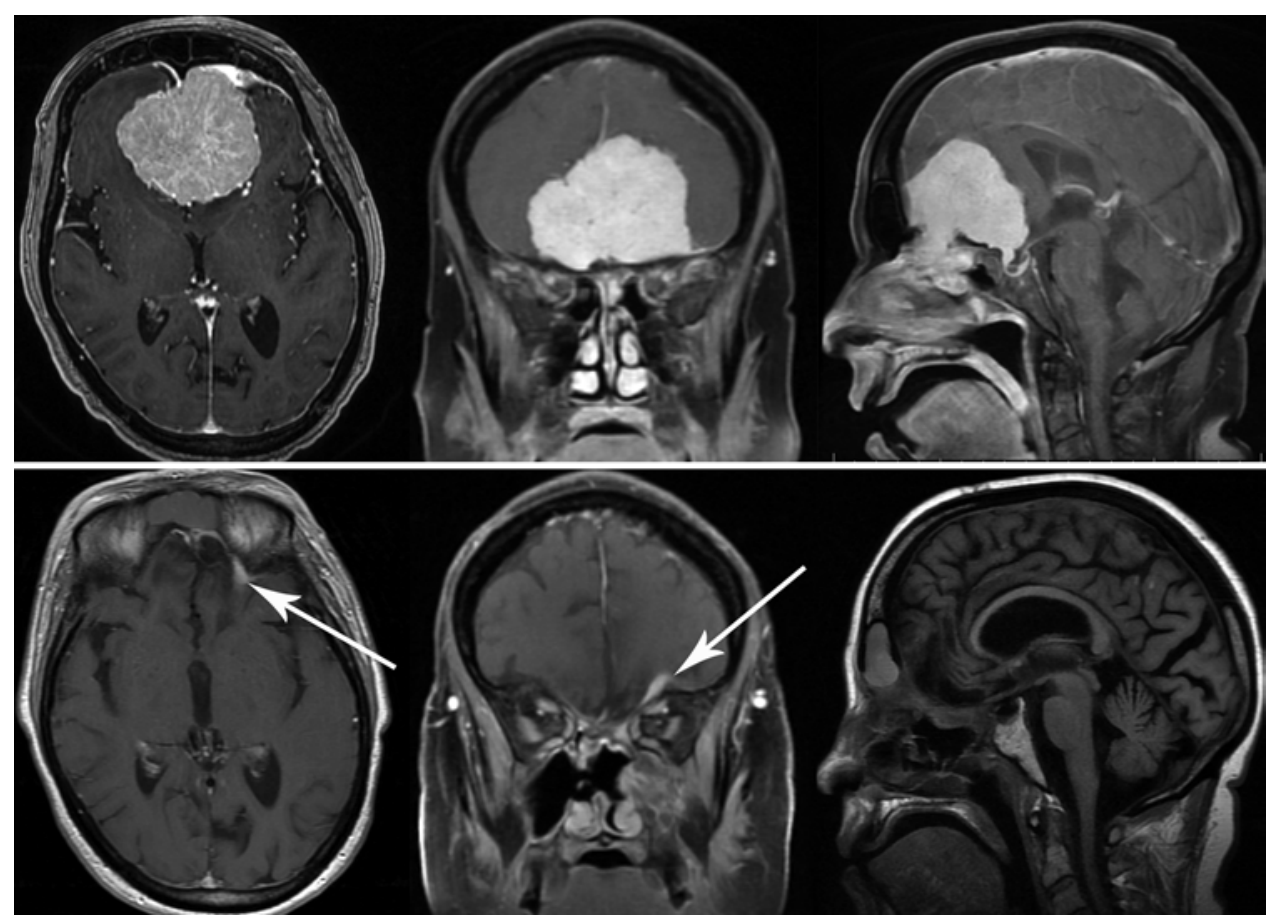

FIG. 3. An NTR of olfactory groove meningioma with staged EES. Upper: Preoperative axial, coronal, and sagittal MRI studies obtained with contrast illustrating a rounded meningioma with maximum diameter of $60 \mathrm{~mm}$ originating from the cribriform plate and planum sphenoidale and extending toward the tuberculum sellae. Clinical presentation included decreased cognition and ambulation, visual and memory loss, and headaches. Lower: Axial and coronal MRI studies obtained with contrast and sagittal MRI obtained without contrast 9 months after a staged EEA. A small residual lesion is left on the left orbital roof (arrows). The patient grossly improved clinically, and during the 22 months of follow-up she has remained stable clinically and radiographically.

\section{Discussion}

Advanced technology and the evolution of skull base surgical techniques have resulted in a parallel evolution and increase in successful outcomes of anterior skull base meningioma surgery. The leading reason for improved surgical results is the use of the operating microscope in contemporary skull base approaches. ${ }^{4,9,15,31,40}$ The goal of cranial base approaches is removal of superficial bone to increase surgical access and totally resect basal tumors such as olfactory groove meningiomas with minimal brain retraction, avoidance of vascular injury, and minimization of the risk of optic nerve damage when the tumor extends posteriorly, all with acceptable cosmetic results.

\section{Surgical Approaches and Limitations}

Currently, the most common traditional approaches for olfactory groove meningioma surgery follow 2 main trajectories: 1) anterior (bilateral or unilateral subfrontal) and 2) lateral (pterional or frontotemporal) approaches, each with its own set of possible modifications (orbital or orbitozygomatic osteotomies), advantages, and limitations. ${ }^{6}$ With our EES experience, we propose a third trajectory, the inferior, for the management of olfactory groove meningiomas.

Anterior (Subfrontal and Supraorbital) Approach. The unilateral or bilateral subfrontal approach for the treatment of suprasellar meningiomas has been previously described in detail., $2,938,40$ The bifrontal frontobasal approach and its variations have long been recommended as the standard technique for removal of large olfactory groove meningiomas. ${ }^{6,21,22,29,31,32,36,40}$ The bifrontal craniotomy has the advantage of allowing the least amount of retraction on the frontal lobes and providing direct access to almost all sides of the tumor. ${ }^{6,21,22,29,31,32,40}$ Disadvantages of the bilateral approach include possible venous infarction due to occlusion of the superior sagittal sinus, potential loss of olfaction, late visualization of vital neurovascular structures, and difficulty in reaching the undersurface of the optic nerves and tuberculum sellae region when the tumor extends posteriorly. For smaller olfactory groove meningiomas, a unilateral subfrontal approach was preferred by some authors to avoid some of these disadvantages ${ }^{6,31,32,38,40}$ The addition of an orbital osteotomy can diminish brain retraction, ${ }^{39}$ but can be time-consuming and may increase the risk of CSF fistula caused by wide opening of the frontal sinus. ${ }^{31}$ The supraorbital approach represents a less invasive lateral approach to the anterior skull base with clinical outcomes similar to those with the pterional approach, but with less brain retraction and lower CSF leak rates in many cases. ${ }^{35}$ With any of these approaches, posterior tumor extension, especially below the level of the tuberculum sellae, is difficult to visualize and resection may be blind in this area.

Lateral (Pterional) Approach. The pterional or frontolateral approach became popular with the development of microsurgical techniques. ${ }^{6,15,34,42}$ It is indicated for smaller olfactory groove meningiomas, with the advantage of early exposure of the ipsilateral supraclinoid 
M. Koutourousiou et al.

TABLE 5: Degree of tumor resection evaluated for different parameters in 45 patients with olfactory groove meningiomas

\begin{tabular}{|c|c|c|c|}
\hline Parameter & No. of Patients & No. w/ GTR (\%) & $p$ Value $^{*}$ \\
\hline age $<65$ yrs & 35 & $24(68.6)$ & 0.710 \\
\hline age $\geq 65$ yrs & 10 & $6(60.0)$ & \\
\hline primary & 40 & $28(70.0)$ & 0.315 \\
\hline recurrent & 5 & $2(40.0)$ & \\
\hline tumor size $\leq 40 \mathrm{~mm}$ & 21 & $19(90.5)$ & 0.002 \\
\hline tumor size $>40 \mathrm{~mm}$ & 24 & $11(45.8)$ & \\
\hline tumor vol $\leq 30 \mathrm{~cm}^{3}$ & 26 & $20(76.9)$ & 0.088 \\
\hline tumor vol >30 $\mathrm{cm}^{3}$ & 19 & $10(52.6)$ & \\
\hline tumor shape rounded & 35 & $24(68.6)$ & 0.710 \\
\hline tumor shape lobular & 10 & $6(60.0)$ & \\
\hline vascular encasement & 6 & $5(83.3)$ & 0.647 \\
\hline no vascular encasement & 39 & $25(64.1)$ & \\
\hline hyperostotic bone & 28 & $17(60.7)$ & 0.096 \\
\hline no hyperostotic bone $\dagger$ & 15 & $13(86.7)$ & \\
\hline calcified tumor & 12 & $5(41.7)$ & 0.024 \\
\hline noncalcified tumor† & 31 & $25(80.6)$ & \\
\hline cortical cuff & 16 & $14(87.5)$ & 0.028 \\
\hline no cortical cuff & 29 & $16(55.2)$ & \\
\hline total & 45 & $30(66.7)$ & \\
\hline
\end{tabular}

* Significant $p$ values are in boldface.

$†$ Two cases without preoperative CT/CTA were excluded from analysis.

carotid artery, optic nerve, and ACA, with CSF draining from the opticocarotid cistern to decrease brain retraction. , $20,31,42$ The pterional approach is less time-consuming than the anterior approaches and usually avoids CSF leakage because the frontal sinus is not transgressed..$^{39}$
Early access to the basal cisterns allows for CSF drainage, providing fair brain relaxation. However, visualization of the contralateral side of the tumor and the medial aspect of the ipsilateral optic nerve and carotid artery might be inadequate. Another disadvantage is the narrow working

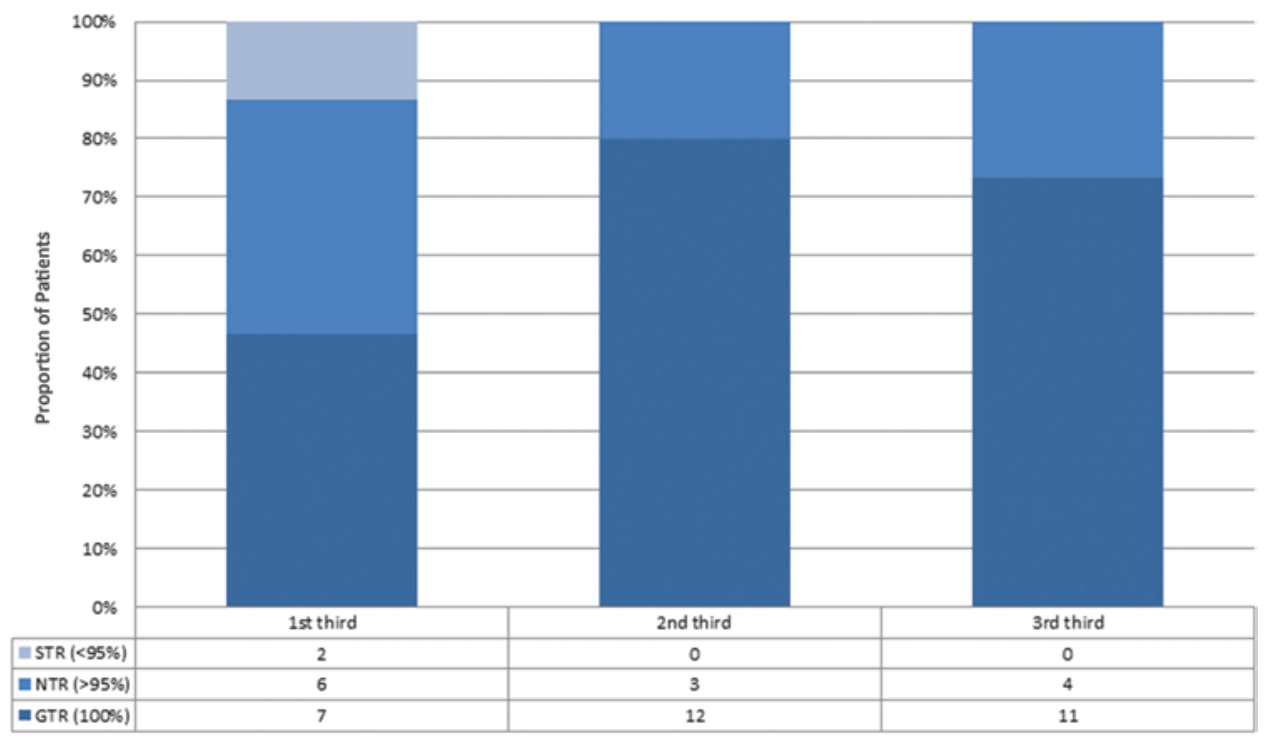

FIG. 4. Bar graph showing the impact of the learning curve in GTR of olfactory groove meningiomas in thirds of patients. The cohort of 45 patients in whom GTR was planned was separated in 3 groups of 15 patients each, who were surgically treated in chronological order. 1st third: February 2003 to June 2006; 2nd third: January 2007 to March 2009; 3rd third: April 2009 to December 2012. After the experience with the first 15 cases, every olfactory groove meningioma has undergone a resection of $>$ $95 \%$ of the tumor, and the GTR rate has reached $>70 \%$. 

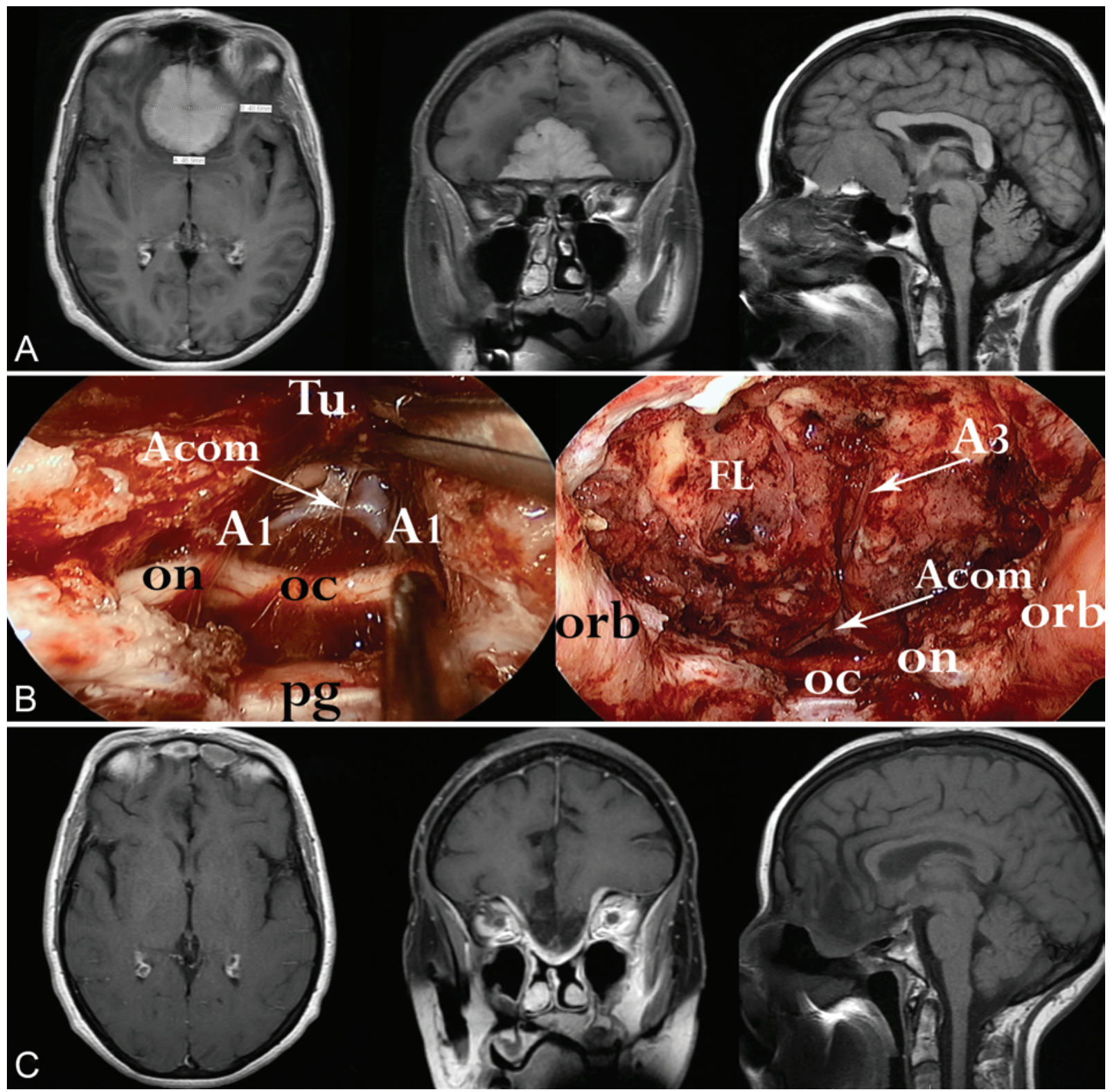

FIG. 5. An NTR of olfactory groove meningioma with staged EES. A: Preoperative axial and coronal MRI studies obtained with contrast and sagittal MRI obtained without contrast showing an olfactory groove meningioma with maximum diameter of $50 \mathrm{~mm}$ extending toward the planum sphenoidale and tuberculum sellae. B: Intraoperative image (left) obtained with a $0^{\circ}$ endoscope during resection of the most posterior part of the tumor (Tu). The optic nerve (on) bilaterally, the optic chiasm (oc), and pituitary gland (pg) can be visualized. By lifting up the tumor, bilateral $A_{1}, A c o m$, and $A_{2}$ are revealed. Intraoperative panoramic visualization of the tumor bed after resection of the tumor (right). The frontal lobes (FL) bilaterally, the left $A_{3}$, the ACA complex, optic nerves, and optic chiasm are free of tumor. The medial wall of the optic canals and orbits (orb) have been removed. C: Postoperative axial and coronal MRI studies obtained with contrast and sagittal MRI obtained without contrast demonstrating an NTR with minimum residual lesion left above the orbital roofs bilaterally.

angle; in high-riding tumors, the upper part of the lesion is in a blind area, and significant brain retraction may be demanded to visualize it. ${ }^{21,39}$

Inferior (EES) Approach. The surgical technique of EES for anterior skull base tumors has already been described in detail. $7,12,13,17,18,24,26,37$ As a result of this direct approach to the tumor from below, EES provides wide visualization of the whole skull base, complete resection of all abnormal bone and mucosa underlying the tumor, early devascularization of the meningioma, and direct visualization of the neurovascular structures of the suprasellar and infrachiasmatic region from below, allowing for a safe tumor resection with minimal neurovascular manipulations (Figs. 5 and 6). In essence, an EEA turns an olfactory groove meningioma into a convexity tumor. Tumors that extend posteriorly, even below the level of the tuberculum sellae, are not a limitation of EES. Additional potential advantages of EES include easy decompression of bilateral optic canals, lack of brain retraction and the 
M. Koutourousiou et al.

TABLE 6: Complications after EES in 50 patients with olfactory groove meningiomas*

\begin{tabular}{|c|c|c|c|c|c|c|c|}
\hline \multirow[b]{2}{*}{ Complication } & \multicolumn{2}{|c|}{ Age (\%) } & \multicolumn{2}{|c|}{ Tumor Size (\%) } & \multicolumn{2}{|c|}{ No. of EESs (\%) } & \multirow{2}{*}{$\begin{array}{l}\text { Total No. of } \\
\text { Cases (\%) }\end{array}$} \\
\hline & $<65$ Yrs & $\geq 65$ Yrs & $\leq 40 \mathrm{~mm}$ & $>40 \mathrm{~mm}$ & Single & Staged & \\
\hline no. of patients & 36 & 14 & 22 & 28 & 32 & 18 & 50 \\
\hline CSF leak & $13(36.1)$ & $2(14.3)$ & 4 (18.2) & $11(39.3)$ & $9(28.1)$ & $6(33.3)$ & $15(30)$ \\
\hline PE/DVT & $5(13.9)$ & $5(35.7)$ & $3(13.6)$ & $7(25.0)$ & $5(15.6)$ & $5(27.8)$ & $10(20)$ \\
\hline sinus infection & $3(8.3)$ & $2(14.3)$ & $2(9.1)$ & $3(10.7)$ & $4(12.5)$ & $1(5.5)$ & $5(10)$ \\
\hline respiratory failure & $2(5.5)$ & $2(14.3)$ & 0 & $4(14.3)$ & $3(9.4)$ & $1(5.5)$ & $4(8)$ \\
\hline hydrocephalus & $1(2.7)$ & $2(14.3)$ & 0 & $3(10.7)$ & $3(9.4)$ & 0 & $3(6)$ \\
\hline brain abscess $†$ & $2(5.5)$ & $1(7.1)$ & 0 & $3(10.7)$ & $1(3.1)$ & $2(11.1)$ & $3(6)$ \\
\hline new seizures $\ddagger$ & $2(5.5)$ & 0 & 0 & $2(7.1)$ & 0 & $2(11.1)$ & $2(4)$ \\
\hline meningitis (post CSF leak) & $1(2.7)$ & 0 & 0 & $1(3.6)$ & 0 & $1(5.5)$ & $1(2)$ \\
\hline vascular injury & $1(2.7)$ & 0 & 0 & $1(3.6)$ & 0 & $1(5.5)$ & $1(2)$ \\
\hline
\end{tabular}

* Differing complication rates in different age groups, tumor size, and number of surgeries were not significant.

$\dagger$ Abscesses formed several months or years after surgery.

$\ddagger$ Seizures occurred 2 years postoperatively, with no or minimal $(<5 \%)$ residual tumor.

resultant consequences, fast recovery, and avoidance of craniotomy-with excellent cosmetic result, shorter surgical time, and shorter hospital stay. The main disadvantage of EES is the increased risk of CSF leakage, which necessitates repeat surgeries for repair and a potentially higher risk of postoperative meningitis and abscess. Although the evolution of the vascularized reconstruction technique with the nasoseptal flap has dramatically decreased the CSF leak rates in suprasellar meningioma surgery, ${ }^{19,25,26,43}$ there are still concerns about the ideal

TABLE 7: Risk factors for CSF leaks following EES for olfactory groove meningiomas

\begin{tabular}{|c|c|c|c|}
\hline Parameter & No. of Patients & No. w/ CSF Leak (\%) & $p$ Value* \\
\hline age $<65$ yrs & 36 & $13(36.1)$ & 0.294 \\
\hline age $\geq 65$ yrs & 14 & $2(14.3)$ & \\
\hline primary & 44 & $12(27.3)$ & 0.348 \\
\hline recurrent & 6 & $3(50.0)$ & \\
\hline tumor size $\leq 40 \mathrm{~mm}$ & 22 & $4(18.2)$ & 0.106 \\
\hline tumor size >40 mm & 28 & $11(39.3)$ & \\
\hline tumor vol $\leq 30 \mathrm{~cm}^{3}$ & 28 & $7(25.0)$ & 0.384 \\
\hline tumor vol $>30 \mathrm{~cm}^{3}$ & 22 & $8(36.4)$ & \\
\hline tumor shape rounded & 40 & $9(22.5)$ & 0.048 \\
\hline tumor shape lobular & 10 & $6(60.0)$ & \\
\hline vascular encasement & 7 & $4(57.1)$ & 0.177 \\
\hline no vascular encasement & 43 & $11(25.6)$ & \\
\hline hyperostotic bone & 31 & $10(32.3)$ & 0.741 \\
\hline no hyperostotic bone† & 17 & $4(23.5)$ & \\
\hline calcified tumor & 13 & $5(38.5)$ & 0.481 \\
\hline noncalcified tumor† & 35 & $9(25.7)$ & \\
\hline cortical cuff & 16 & $3(18.7)$ & 0.328 \\
\hline no cortical cuff & 34 & $12(35.3)$ & \\
\hline GTR & 30 & $6(20.0)$ & 0.059 \\
\hline non-GTR & 20 & $9(45.0)$ & \\
\hline single EES & 32 & $9(28.1)$ & 0.700 \\
\hline staged EES & 18 & $6(33.3)$ & \\
\hline total & 50 & $15(30.0)$ & \\
\hline
\end{tabular}

* Significant $p$ values are in boldface.

$\dagger$ Two cases without preoperative CT/CTA were excluded from analysis. 


\section{Endoscopic endonasal surgery for olfactory groove meningiomas}
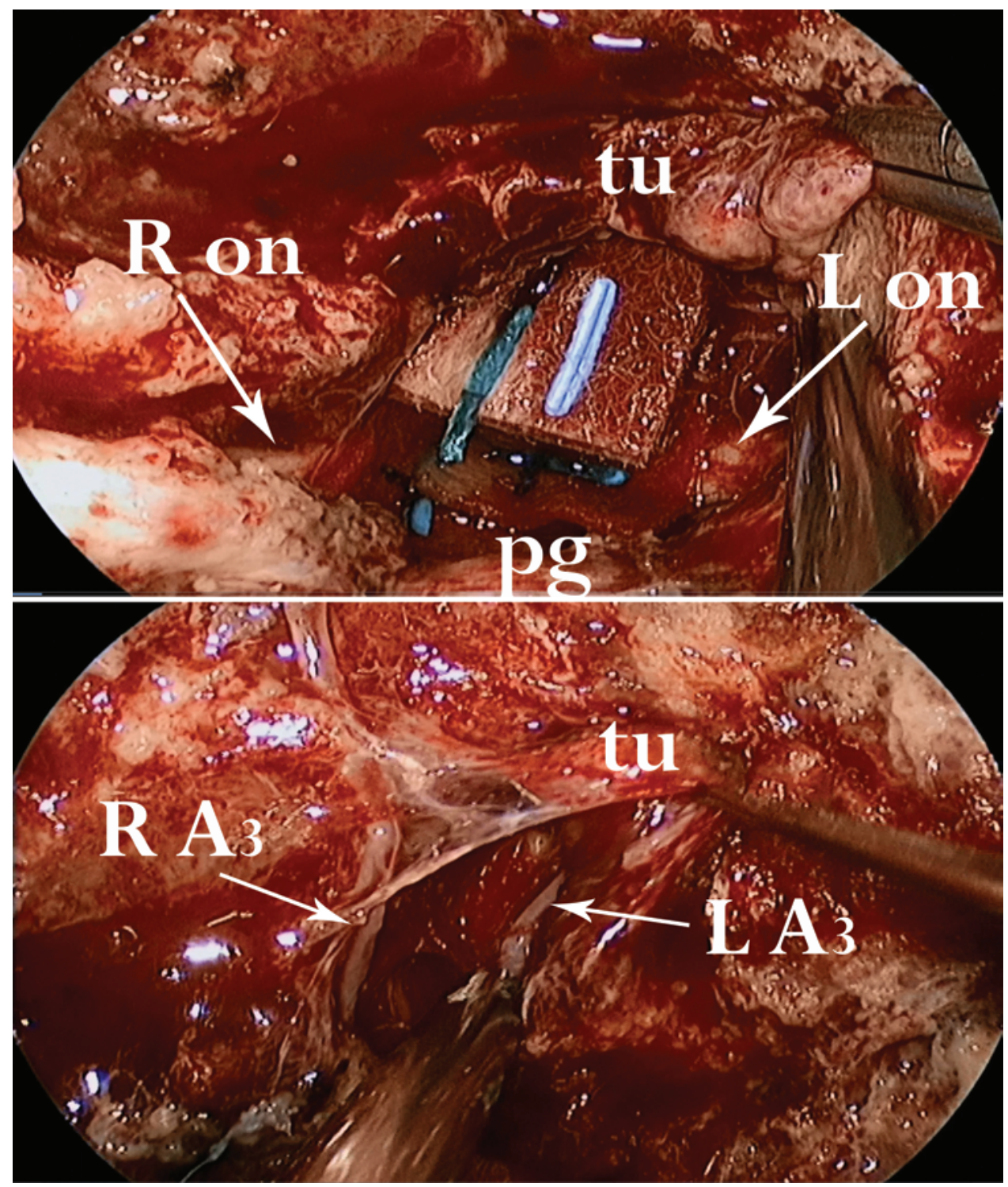

FIG. 6. Intraoperative images obtained with a $0^{\circ}$ endoscope during EES for resection of olfactory groove meningioma. Upper: The tuberculum sellae and planum sphenoidale have been removed; the intracranial optic nerves (on) are identified bilaterally; the pituitary gland $(\mathrm{pg})$ is visualized; and the ACA complex is protected with patties during resection of the most posterior part of the tumor (tu). Lower: The cribriform plate and crista galli, lamina papyracea, and orbital roofs bilaterally have been removed; and the $\mathrm{A}_{3}$ segments of the ACAs bilaterally have been identified and preserved during dissection of the most anterior part of the tumor. $L=$ left; $R=$ right.

reconstruction technique in the larger olfactory groove meningiomas, as discussed below.

\section{Surgical Outcome}

Gross-Total Resection. Gross-total tumor resection remains the goal of meningioma surgery in most cases, regardless of approach. However, GTR should be tempered by the risk of morbidity, which was higher before the introduction of microscopic techniques.10,15,31 Evaluation of the degree of tumor resection among published series of open approaches for olfactory groove meningiomas is not always straightforward because of the different definitions of "complete" resection. Several authors have reported complete resection rates of $\geq 90 \%$, but only by including both Simpson Grade I and II, or without association of the degree of resection with the Simpson grading system..$^{31,35,39,42}$ As expected, authors who define GTR as Simpson Grade I only have reported lower GTR rates, ranging from $23.8 \%$ to $84.6 \% .^{1,4,22}$ We use the same strict definition of GTR as Simpson Grade I only, and we also confirm the lack of residual meningioma in every case with postoperative MRI, which is critical for objective evaluation of resection. With these criteria, the GTR rate of EES is $66.7 \%$ when GTR is the goal of surgery, in line with the largest published series of Simpson Grade I resection performed via traditional open approaches.

Limiting Factors. Factors that limit olfactory groove meningioma removal with EES are factors that increase 


\section{Koutourousiou et al.}

the risk and difficulty associated with traditional approaches as well. Based on the statistical analysis of our results as presented in Table 5, tumor size is the most important factor that can limit GTR, especially for tumors $>40 \mathrm{~mm}$. This is not a limitation only for EES; in large tumors the arachnoid plane may not be intact, which can contribute to the risk of neurovascular injuries. Size, especially as it relates to lateral and anterior tumor extension, is the main selection criterion for an open surgical approach, as already discussed. Various authors have considered the size of the tumor to be a crucial factor that indicates possible surgical difficulties and increased morbidity, especially for tumors $>40 \mathrm{~mm} .^{6,21,22,31,41}$ However, there are reports that tumor size is not correlated with residual lesion. ${ }^{35}$ With the endoscopic experience, Simpson Grade I resection can be achieved in $90.5 \%$ of olfactory groove meningiomas $\leq 40 \mathrm{~mm}$, but only in $45.8 \%$ of tumors $>40 \mathrm{~mm}$.

The presence of calcified olfactory groove meningiomas has not been described in the craniotomy literature as a potential limitation of tumor resection, although it is unclear if this has been evaluated. This unique finding of our analysis may reflect the lack of ideal instrumentation that could be introduced from the narrow nasal corridor and facilitate an easy and safe resection of "hard" tumors, or it may reflect a reliance on tumor descent, something that is less likely if the lesion is heavily calcified. Indeed, the main technique of endoscopic tumor resection in the early years was the use of angled scissors and cutting instruments, whereas technologically advanced instrumentation like the side-cutting aspiration device or ultrasonic surgical aspirators have only been very recently introduced in EES, and they may need further improvement for adequate results. ${ }^{3,30,33}$ The absence of cortical cuff as a factor in reduced GTR rates in EES actually reflects the absence of clear arachnoid plane between the tumor and the brain parenchyma/neurovascular structures, which represents a challenge regardless of the surgical approach. Although advanced age was not a limitation for GTR with EES (Table 5), advanced age and coexisting comorbidities were the main indicators that changed the goal of surgery toward less aggressive resections. The association between elderly age and adverse outcome after meningioma surgery is well described in the literature and suggests a note of caution and a clear limitation in surgery planning for this age group.

Residual lesion due to close adherence to neurovascular structures would not be avoided with a different approach; however, residual on the most lateral and anterior margins of the tumor probably represents a limitation of EES. Angled endoscopes are used throughout EES for olfactory groove meningiomas and allow visualization of the most marginal aspects of the tumor, but adequate instrumentation to facilitate safe tumor resection from these areas remains a limitation. It is critical to use a superomedial orbitectomy to extend lateral access during EEA to the midorbital line. Failure to remove the lamina papyracea and orbital roof when necessary will even further limit lateral tumor access.

It is worth noting that at the time of this publication, and given the observation of tumor residual at the most lateral and anterior margins combined with the lack of appropriate endoscopic instrumentation to reach these areas, we may now offer open surgery to patients with wide tumor base (lateral to the midorbital line) and extreme anterior tumor extension (extending up the posterior table of the frontal sinus) without an anterior cuff of overlying frontal lobe. This change emphasizes the value of critically analyzing the outcome of any new approach, recognizing the limitations of the approach, and altering the surgical technique when indicated for the patient's benefit.

Clinical Outcome. The surgical success in terms of improved symptomatology is well demonstrated in the literature, with rates of improvement in mental status or Karnofsky Performance Scale scores ranging from $11 \%$ to $88 \%$ and visual improvement in $55 \%-83 \%$ of cases. ${ }^{4,31,35}$ However, some studies have even shown overall worsening of the Karnofsky Performance Scale score postoperatively. ${ }^{1}$ The inferior-to-superior trajectory that the EEA provides, with the resultant ability to remove tumors compressing the frontal lobes and optic nerves and/or chiasm without their manipulation, are probably the main reasons for the excellent clinical outcomes of EES. The rates of $77.8 \%$ for postoperative cognitive improvement and $86.7 \%$ for vision recovery are among the highest reported in the literature. Specifically for the visual outcome, we believe that the excellent visualization and attendant preservation of microvasculature of the optic nerves and/or chiasm provided by the endoscope, as well as the wide optic nerve decompression in cases of optic canal invasion by the tumor and/or papilledema, explain the superior outcomes compared with open surgeries, a fact that has already been demonstrated in suprasellar meningioma surgery. ${ }^{26}$

Olfaction is not addressed directly in our outcomes because loss is expected. Two patients underwent a unilateral approach in an attempt to preserve olfaction. There are several reports of using a unilateral craniotomy approach to preserve olfaction in the setting of olfactory groove meningiomas; however, by the nature of tumor involvement, this necessitates a higher Simpson grade resection and therefore greater risk of recurrence. ${ }^{23}$ This could be considered for patients in whom olfaction is paramount, but with the inconsistency of preservation and tradeoff for completeness of resection considered.

\section{Surgical Complications}

The evolution of skull base techniques was followed by decreased rates of morbidity and mortality after the introduction of the neurosurgical microscope for the treatment of olfactory groove meningiomas. Thus, mortality rates that reached $33 \%$ in the premicroscope era have declined in recent years. ${ }^{21,31,36,39,40,42}$ Major potential surgical complications include postoperative seizures, intracranial hemorrhage, subdural hygroma, worsening vision, motor deficits, CSF leakage, and meningitis. ${ }^{1,4,11,21,22,31,35,39}$

The lack of brain manipulation by retraction is reflected by a comparison of postoperative complications. Postoperative generalized seizures occur following craniotomy for olfactory meningioma in $3.8 \%-11.8 \%$ of cases. ${ }^{11,31,39}$ Seizure is an exceedingly rare complication following EES, and the 2 cases in which this occurred were years 


\section{Endoscopic endonasal surgery for olfactory groove meningiomas}

after EES. Other surgical complications, such as subdural hygroma, which were found to occur in $17.6 \%$ of cases after transcranial approaches, ${ }^{31}$ were not observed after EES. Postoperative edema following bifrontal approaches was found in $15.2 \%$ of cases in the experience of Nakamura et al., ${ }^{31}$ but this complication was never encountered in the EES experience. This lack of edema with EEA is reflected in recent findings by DeAlmeida et al. (unpublished data, 2014) comparing postoperative encephalomalacia cavity and FLAIR change on MRI in a matched case series that shows less radiographic impact of the frontal lobes following EEA. Although this finding does not have a clear clinical correlation, it presents a compelling argument for potentially improved cognitive outcomes.

Cerebrospinal fluid leakage remains a challenge for EES for olfactory groove meningioma. In transcranial olfactory groove meningioma surgery, the pterional approach is associated with a lower risk of postoperative CSF leakage given the avoidance of the frontal sinus. ${ }^{20,21,31,42}$ Still, CSF leakage after transcranial surgery can be quite high, and rates reaching $19 \%$ have been reported in the literature. $111,31,32,35,39$ As an approach to the tumor through the ethmoidal sinuses, EES is associated with higher rates of CSF leakage, a fact that has motivated endoscopic skull base surgeons to develop new reconstruction techniques. And, although the innovation of the vascularized nasoseptal reconstruction technique has dramatically decreased the CSF leak rates in other pathological entities, the extensive skull base defect after olfactory groove meningioma surgery remains a reconstruction challenge..$^{19,25-28,43}$ Our technique has changed since this series to include a 3-layer technique as described by Eloy et al..$^{14}$ In addition, the more recent use of the wider and longer extracranial pericranial flap has shown no failure so far (our unpublished data, 2014), and it may represent the ideal available technique to avoid CSF leakage following EES for olfactory groove meningioma. Further advances and innovative materials for skull base reconstruction are needed and expected to minimize this complication. Despite the high rate of CSF leakage, postoperative meningitis occurred in only $2 \%$ of cases after EES, in line with the literature on transcranial approaches.

Local wound infection has been reported after craniotomies in $<6 \%$ of cases, $, 11,31,35$ with few reports of intracranial abscess formation. ${ }^{35}$ The evidence of $6 \%$ intracranial abscess formation in this study, even in the absence of CSF leakage, was surprising given the lack of this complication in the treatment of other lesions with EES. It was associated with tumors $>40 \mathrm{~mm}$ and multiple surgeries in every case, again raising concerns about the optimal reconstruction of large olfactory groove meningiomas. More general complications like postoperative PE/DVT have been reported in the transcranial literature in rates $<10 \%,{ }^{11,39}$ the EES experience showed a rate of $20 \%$ usually associated with the treatment of the elderly, staged surgeries, and tumors $>40 \mathrm{~mm}$. This may all be related to a subgroup of patients with longer length of stay, probably related to CSF leakage. As with open surgery, there was a trend toward greater rates of complication with tumors $>$ $40 \mathrm{~mm}$, although this did not reach significance.

Death following craniotomy for olfactory groove me- ningiomas used to be more frequent in the premicroscope era, but these rates have decreased with the evolution of microscopic approaches $11,21,31,36,39,40,42$ and now range from $5 \%$ to $17 \% .^{1,4,11,31,35,38,39}$ Endoscopic endonasal surgery remains a safe approach for olfactory groove meningiomas, with $0 \%$ perioperative mortality in this series.

\section{Tumor Recurrence}

As stated by Al-Mefty and others, failure to resect all involved tissues, including the bone and dura of the anterior skull base, is the most significant factor that determines recurrence. ${ }^{21,32,39}$ Following this principle, we try to achieve Simpson Grade I resection with EES, which facilitates resection of the involved bone and mucosa better than any open approach. However, in wide-based meningiomas we have noticed residual dura tail on top of the orbital roofs or at the most anterior skull base margins, which represents limitations of EES. We have altered our approach, and may offer transcranial surgery for olfactory groove meningiomas with a wide base extending lateral to the midorbital line or extending to the posterior table of the frontal sinus, to avoid leaving residual lesion and risking tumor regrowth in the future. So far the recurrence rate of EES is only 6\%, but the nascent application of this approach does not allow for long-term follow-up and certainty in terms of recurrence rates.

\section{Conclusions}

\section{Indications for EES}

Technological advances and increasing surgical experience have expanded the indications for EES to the management of large anterior skull base tumors like olfactory groove meningiomas. Based on the current data, EES represents an effective and safe approach for olfactory groove meningiomas, with very good clinical outcomes and rates of resection regardless of patient age, previous treatment, or tumor characteristics.

Given the data presented in this series, EES is best applied in smaller tumors without significant lateral extent (especially beyond the midorbit). In addition, it loses its advantage of limiting brain retraction in tumors with anterior extension, especially superiorly abutting the posterior table of the frontal sinus. On the other hand, posteriorly based tumors with a cuff of frontal lobe between them and the frontal sinus, and especially those with significant edema, may be best suited for an EEA. Involvement of intracranial vasculature is a relative contraindication and depends on the individual surgeon's and team's experience with each approach.

Cerebrospinal fluid leakage remains a challenge for larger tumors, and these should be considered for an extracranial pericranial flap for reconstruction, although this is anecdotal. This allows for preservation of the frontal lobe manipulation advantages of EEA while limiting the multiple complications that can stem from inadequate reconstruction.

\section{Acknowledgments}

We thank Yue-Fang Chang, Ph.D., Research Assistant Profes- 


\section{Koutourousiou et al.}

sor, Department of Neurosurgery, University of Pittsburgh Medical Center, for the statistical analysis of the surgical results. Also, we thank Dr. Amin B. Kassam, Division of Neurosurgery, University of Ottawa, Ontario, Canada; Dr. Ricardo L. Carrau, Department of Otolaryngology-Head \& Neck Surgery, The Ohio State University Medical College, Columbus, Ohio; and Dr. Daniel M. Prevedello, Department of Neurological Surgery, The Ohio State University Medical College, Columbus, Ohio, for their involvement in the clinical and operative management of many of these patients.

\section{Disclosure}

Dr. Gardner is a consultant for Integra LifeSciences, and Dr. Snyderman is a consultant for SPIWay LLC.

Author contributions to the study and manuscript preparation include the following. Conception and design: Koutourousiou. Acquisition of data: Koutourousiou. Analysis and interpretation of data: Koutourousiou. Drafting the article: Koutourousiou. Critically revising the article: Gardner, Koutourousiou, Fernandez-Miranda, Snyderman. Reviewed submitted version of manuscript: Gardner, Koutourousiou, Fernandez-Miranda, Wang, Snyderman. Study supervision: Gardner.

\section{References}

1. Aguiar PH, Tahara A, Almeida AN, Simm R, Silva AN, Maldaun MV, et al: Olfactory groove meningiomas: approaches and complications. J Clin Neurosci 16:1168-1173, 2009

2. Arai H, Sato K, Okuda, Miyajima M, Hishii M, Nakanishi H, et al: Transcranial transsphenoidal approach for tuberculum sellae meningiomas. Acta Neurochir (Wien) 142:751-757, 2000

3. Baddour HM, Lupa MD, Patel ZM: Comparing use of the Sonopet ${ }^{\circledR}$ ultrasonic bone aspirator to traditional instrumentation during the endoscopic transsphenoidal approach in pituitary tumor resection. Int Forum Allergy Rhinol 3:588-591, 2013

4. Bassiouni H, Asgari S, Stolke D: Olfactory groove meningiomas: functional outcome in a series treated microsurgically. Acta Neurochir (Wien) 149:109-121, 2007

5. Bateman BT, Pile-Spellman J, Gutin PH, Berman MF: Meningioma resection in the elderly: nationwide inpatient sample, 1998-2002. Neurosurgery 57:866-872, 2005

6. Bogaev CA, Sekhar LN: Olfactory groove and planum sphenoidale meningiomas, in Sekhar LN, Fessler RG (eds): Atlas of Neurosurgical Techniques: Brain. New York: Thieme, 2006, pp 608-617

7. Cappabianca P, Cavallo LM, Esposito F, De Divitiis O, Messina A, De Divitiis E: Extended endoscopic endonasal approach to the midline skull base: the evolving role of transsphenoidal surgery. Adv Tech Stand Neurosurg 33:151-199, 2008

8. Cappabianca P, Cavallo LM, Esposito F, Solari D: Sellar/tuberculum approach, in Kassam AB, Gardner PA (eds): Endoscopic Approaches to the Skull Base. Progress in Neurological Surgery, Volume 26. Basel: Karger, 2012, pp 41-59

9. Chokyu I, Goto T, Ishibashi K, Nagata T, Ohata K: Bilateral subfrontal approach for tuberculum sellae meningiomas in long-term postoperative visual outcome. Clinical article. J Neurosurg 115:802-810, 2011

10. Ciric I, Rosenblatt S: Suprasellar meningiomas. Neurosurgery 49:1372-1377, 2001

11. Ciurea AV, Iencean SM, Rizea RE, Brehar FM: Olfactory groove meningiomas: a retrospective study on 59 surgical cases. Neurosurg Rev 35:195-202, 2012

12. de Divitiis E, Cavallo LM, Cappabianca P, Esposito F: Extended endoscopic endonasal transsphenoidal approach for the removal of suprasellar tumors: Part 2. Neurosurgery 60:46-59, 2007

13. Dehdashti AR, Ganna A, Witterick I, Gentili F: Expanded endoscopic endonasal approach for anterior cranial base and suprasellar lesions: indications and limitations. Neurosurgery 64:677-689, 2009
14. Eloy JA, Shukla PA, Choudhry OJ, Singh R, Liu JK: Assessment of frontal lobe sagging after endoscopic endonasal transcribriform resection of anterior skull base tumors: is rigid structural reconstruction of the cranial base defect necessary? Laryngoscope 122:2652-2657, 2012

15. Fahlbusch R, Schott W: Pterional surgery of meningiomas of the tuberculum sellae and planum sphenoidale: surgical results with special consideration of ophthalmological and endocrinological outcomes. J Neurosurg 96:235-243, 2002

16. Fernandez-Miranda JC, Pinheiro-Nieto C, Gardner PA, Snyderman $\mathrm{CH}$ : Endoscopic endonasal approach for a tuberculum sellae meningioma. J Neurosurg 32 Suppl:Video 8, 2012

17. Gardner PA, Kassam AB, Thomas A, Snyderman CH, Carrau RL, Mintz AH, et al: Endoscopic endonasal resection of anterior cranial base meningiomas. Neurosurgery 63:36-54, 2008

18. Gardner PA, Vescan A, de Almeida JR, Janjua A, Kassam AB, Prevedello DM, et al: Endoscopic endonasal approach for olfactory groove meningiomas, in Kassam AB, Gardner PA (eds): Endoscopic Approaches to the Skull Base. Progress in Neurological Surgery, Volume 26. Karger: Basel, 2012, pp 76-86

19. Hadad G, Bassagasteguy L, Carrau RL, Mataza JC, Kassam A, Snyderman $\mathrm{CH}$, et al: A novel reconstructive technique after endoscopic expanded endonasal approaches: vascular pedicle nasoseptal flap. Laryngoscope 116:1882-1886, 2006

20. Hassler W, Zentner J: Surgical treatment of olfactory groove meningiomas using the pterional approach. Acta Neurochir Suppl (Wien) 53:14-18, 1991

21. Hentschel SJ, DeMonte F: Olfactory groove meningiomas, in DeMonte F, McDermott MW, Al-Mefty O (eds): Al-Mefty's Meningiomas, ed 2. New York: Thieme, 2011, pp 196-205

22. Hentschel SJ, DeMonte F: Olfactory groove meningiomas. Neurosurg Focus 14(6):E4, 2003

23. Jang WY, Jung S, Jung TY, Moon KS, Kim IY: Preservation of olfaction in surgery of olfactory groove meningiomas. Clin Neurol Neurosurg 115:1288-1292, 2013

24. Kassam A, Snyderman CH, Mintz A, Gardner P, Carrau RL: Expanded endonasal approach: the rostrocaudal axis. Part I. Crista galli to the sella turcica. Neurosurg Focus 19(1):E3, 2005

25. Kassam AB, Thomas A, Carrau RL, Snyderman CH, Vescan A, Prevedello D, et al: Endoscopic reconstruction of the cranial base using a pedicled nasoseptal flap. Neurosurgery 63 (1 Suppl 1):ONS44-ONS53, 2008

26. Koutourousiou M, Fernandez-Miranda JC, Stefko ST, Wang EW, Snyderman $\mathrm{CH}$, Gardner PA: Endoscopic endonasal surgery for suprasellar meningiomas: experience with 75 patients. Clinical article. J Neurosurg 120:1326-1339, 2014

27. Koutourousiou M, Gardner PA, Fernandez-Miranda JC, Paluzzi A, Wang EW, Snyderman CH: Endoscopic endonasal surgery for giant pituitary adenomas: advantages and limitations. Clinical article. J Neurosurg 118:621-631, 2013

28. Koutourousiou M, Gardner PA, Fernandez-Miranda JC, TylerKabara EC, Wang EW, Snyderman CH: Endoscopic endonasal surgery for craniopharyngiomas: surgical outcome in 64 patients. Clinical article. J Neurosurg 119:1194-1207, 2013

29. Long DM: Meningiomas of the olfactory groove and anterior fossa, in: Atlas of Operative Neurosurgical Technique: Cranial Operations. Baltimore: Williams \& Wilkins, 1989, Vol 1, pp 238-241

30. McLaughlin N, Ditzel Filho LF, Prevedello DM, Kelly DF, Carrau RL, Kassam AB: Side-cutting aspiration device for endoscopic and microscopic tumor removal. J Neurol Surg B Skull Base 73:11-20, 2012

31. Nakamura M, Struck M, Roser F, Vorkapic P, Samii M: Olfactory groove meningiomas: clinical outcome and recurrence rates after tumor removal through the frontolateral and bifrontal approach. Neurosurgery 62 (6 Suppl 3):1224-1232, 2008 


\section{Endoscopic endonasal surgery for olfactory groove meningiomas}

32. Obeid F, Al-Mefty O: Recurrence of olfactory groove meningiomas. Neurosurgery 53:534-543, 2003

33. Oertel J, Krauss JK, Gaab MR: Ultrasonic aspiration in neuroendoscopy: first results with a new tool. Technical note. J Neurosurg 109:908-911, 2008

34. Pamir MN, Ozduman K, Belirgen M, Kilic T, Ozek MM: Outcome determinants of pterional surgery for tuberculum sellae meningiomas. Acta Neurochir (Wien) 147:1121-1130, 2005

35. Romani R, Lehecka M, Gaal E, Toninelli S, Celik O, Niemelä $\mathrm{M}$, et al: Lateral supraorbital approach applied to olfactory groove meningiomas: experience with 66 consecutive patients. Neurosurgery 65:39-53, 2009

36. Samii M, Ammirati M: Olfactory groove meningiomas, in: Surgery of the Skull Base: Meningiomas. Berlin: Springer Verlag, 1992, pp 15-25

37. Snyderman CH, Pant H, Carrau RL, Prevedello D, Gardner P, Kassam AB: What are the limits of endoscopic sinus surgery?: the expanded endonasal approach to the skull base. Keio J Med 58:152-160, 2009

38. Solero CL, Giombini S, Morello G: Suprasellar and olfactory meningiomas. Report on a series of 153 personal cases. Acta Neurochir (Wien) 67:181-194, 1983

39. Spektor S, Valarezo J, Fliss DM, Gil Z, Cohen J, Goldman J, et al: Olfactory groove meningiomas from neurosurgical and ear, nose, and throat perspectives: approaches, techniques, and outcomes. Neurosurgery 57 (4 Suppl):268-280, 2005
40. Symon L: Olfactory groove and suprasellar meningiomas, in Krayenbühl H, Brihaye J, Loew V, et al (eds): Advances and Technical Standards in Neurosurgery. Vienna: Springer Verlag, 1977, Vol 4, pp 67-91

41. Tomasello F, Angileri FF, Grasso G, Granata F, De Ponte FS, Alafaci C: Giant olfactory groove meningiomas: extent of frontal lobes damage and long-term outcome after the pterional approach. World Neurosurg 76:311-317, 255-258, 2011

42. Turazzi S, Cristofori L, Gambin R, Bricolo A: The pterional approach for the microsurgical removal of olfactory groove meningiomas. Neurosurgery 45:821-826, 1999

43. Zanation AM, Carrau RL, Snyderman CH, Germanwala AV, Gardner PA, Prevedello DM, et al: Nasoseptal flap reconstruction of high flow intraoperative cerebral spinal fluid leaks during endoscopic skull base surgery. Am J Rhinol Allergy 23:518-521, 2009

Manuscript submitted June 15, 2014.

Accepted July 17, 2014.

Please include this information when citing this paper: DOI: 10.3171/2014.7.FOCUS14330.

Address correspondence to: Paul Gardner, M.D., Department of Neurosurgery, University of Pittsburgh Medical Center Presbyterian, 200 Lothrop St., Ste. B400, Pittsburgh, PA 15213. email: gardpa@ upmc.edu. 